


\title{
LA DECLARACIÓN DE UNIJES SOBRE LA REGENERACIÓN DEMOCRÁTICA DE LA VIDA PÚBLICA EN ESPAÑA
}

\author{
Autor: Raúl González Fabre. ${ }^{1}$ \\ Facultad de Ciencias Económicas y Empresariales. \\ Universidad Pontificia Comillas.
}

\section{Resumen}

Se presentan algunas cuestiones subyacentes a la "Declaración de UNIJES sobre la regeneración democrática de la vida pública en España" (la cual puede leerse completa en el Anexo). En concreto, se subrayan la relación entre ética y política, la relación de la población con el Estado nacional como instrumento de política, la prioridad propuesta de la política sobre la economía, el patrimonialismo en la vida pública española, y el problema del destinatario de la Declaración de UNIJES.

Palabras clave. UNIJES, Estado nacional, ética, política, patrimonialismo, lucha de clases.

The UNIJES Declaration about the Democratic Regeneration of Public Life in Spain.

\footnotetext{
${ }^{1}$ rgfabre@cee.upcomillas.es
} 


\begin{abstract}
Some questions underlying the "UNIJES Declaration about the Democratic Regeneration of Public Life in Spain" are exposed. The Declaration itself can be read in full in the Annex to the article. Questions discussed include: the connection between Ethics and Politics, the popular relationship with the national State as an instrument of policy, the priority of politics over the economy, patrimonialism in the Spanish public life, and to whom the UNIJES Declaration is addressed.
\end{abstract}

Keywords. UNIJES, national State, Ethics, Politics, patrimonialism, class struggle.

Recibido: 13-01-2014

Aceptado: 10-03-2014

\title{
1. INTRODUCCIÓN.
}

Al analizar las salidas de la crisis en diversos aspectos y los significados éticos asociados a ellas, como se hace en este número de ICADE, es inevitable preguntarse por el sujeto que las realizará: quién debe cambiar qué. Cuando esta pregunta se acompaña de una segunda: quién debe hacer que ese tal cambie lo que fuere, si no lo cambia espontáneamente, nos encontramos realmente ante una cuestión política. Sobre ello hay diversas sugerencias en el volumen que el lector tiene entre sus manos.

Conviene sin embargo notar la persistencia en nuestros diálogos sociales de lo que Kahneman (2011) llamaría una heurística: en vez de contestar preguntas difíciles como las anteriores, respondemos en su lugar alguna pregunta más sencilla. Por ejemplo, en vez de quién debe cambiar nos planteamos quién puede cambiar, o mejor, a quién podemos hacer cambiar, y damos la respuesta a esta última pregunta como una aproximación suficientemente buena a la original.

Se van a cumplir pronto 250 años del motín de Esquilache (1766), que son dos siglos y medio de intentos por parte de la población española por ajustar las políticas del Estado nacional a los personales gustos, intereses y opciones de cada cual. En muchas de nuestras conversaciones sociales subyace así el supuesto de que discutimos cambios para ese Estado, si acaso para sus subdivisiones regionales y municipales ahora más o menos autónomas. De tanto suponerlo, hemos dejado de explicitarlo: hablamos implícitamente de aquel a quien podemos hacer cambiar con los instrumentos políticos con los que estamos familiarizados.

Pero, claro está, como hemos visto en este número, el lugar de los cambios sostenibles ya no es uno solo, si es que alguna vez lo fue. Hubo un tiempo en que 
predominaba la ilusión de que todo estribaba en conquistar el poder del Estado nacional. Desde allí se emplearían la educación y los medios de comunicación para modificar la cultura de las masas; la ley y la distribución económica de premios y castigos para poner a los sujetos adecuados en lugares de prominencia social; y el ejército para evitar la injerencia extranjera. Una, grande y libre. Hecho eso, sería posible desarrollar desde el poder un proyecto moral modernizador para la sociedad nacional: ilustrado, socialista o fascista, poco importa.

Incluso en épocas en que la soberanía residía verdaderamente en los Estados nacionales, fueron muchos los países cuyos proyectos modernizadores fracasaron por desconocer la complejidad de los cambios necesarios. De entonces acá, poca gente piensa que haya una sola clave de las transformaciones necesarias (sea la razón encarnada en la ley, la propiedad de los medios de producción, la cohesión nacional...). Se tiende más bien a pensar en cambios de distinto nivel, con sujetos diversos y distintos propósitos, engarzados entre sí de maneras complejas y por ello a menudo imprevisibles. Quizás pueda aspirarse a una cierta armonía entre ellos, que evite las grandes contradicciones internas y trace perfiles de conjunto reconocibles.

Tampoco son muchos quienes piensan que el poder nacional sea el fundamental para desencadenar esos cambios. Mejor dicho, no es mucha la gente que lo piensa argumentadamente a la vista de las realidades contemporáneas. Sigue siendo quizás la mayoría quienes lo piensan inercialmente, a partir de un mundo pasado del que todavía no han salido mentalmente del todo porque opera en sus supuestos. Por así decirlo, lo piensan porque no se han parado a pensarlo.

Sin embargo, el Estado nacional es todavía la organización política más grande sobre la que muchos tenemos alguna esperanza de intervenir directamente. Los movimientos globales de la economía, la política, la cultura, las actitudes de masas... todo ello o nos queda demasiado lejos para sentirnos con algún peso en su gestión, o nos imaginamos interviniendo en ello fundamentalmente a través de nuestro Estado nacional. Incluso poderes regionales como los nacidos de la Unión Europea y la Zona Euro son de ese tipo: agregados sin mayor consistencia política propia en los cuales se participa a través de los Estados nacionales.

La heurística de Kahneman se impone entonces con fuerza: aunque sepamos que debe incidirse sobre niveles y aspectos que el Estado nacional no puede controlar, al final encontramos que al menos a través del Estado nacional queremos incidir en lo que se pueda. En ese sentido se propone aquí leer la Declaración de las Universidades Jesuitas españolas ${ }^{2}$ por relación a la crisis. Muchas cosas habría que cambiar sobre las que no sabemos cuánto podemos influir, pero al menos que funcionen bien aquellas, como el Estado nacional, que sí sabemos que están en nuestra mano.

\footnotetext{
${ }^{2}$ La Declaración es corta por lo que hemos decidido incluirla en un apéndice a este artículo. Los números de ella aludidos en el artículo van entre corchetes [ ].
} 


\section{LA EXISTENCIA DEL DOCUMENTO.}

En un tiempo era común que las autoridades universitarias se pronunciaran sobre las cuestiones sociales del momento, especialmente las de carácter más estructural. No se esperaba de las autoridades universitarias que concentraran su verbo en los problemas presupuestarios derivados de la dependencia del financiamiento público. Con otras palabras, la universidad no se portaba como un grupo especial de intereses preocupado por su porción en el reparto público, sino como un lugar para la discusión política sobre los problemas de conjunto de la sociedad.

En política democrática, la discusión es acción, de manera que en la universidad desde los estudiantes hasta las autoridades pasando por los profesores, realizaban acción política. Politizar a los estudiantes era precisamente uno de los elementos centrales de la educación informal que se daba en la universidad. Se utilizaba una aproximación a la educación en la cual se explicaba y se discutían las implicaciones políticas y sociales de cualquier materia que se presentara en clase. Esa aproximación pasaba a los curricula reales de muchas asignaturas, y se la encontraba también en las actividades extraacadémicas, organizadas por los estudiantes o por la misma universidad.

Evidentemente muchos profesores siguen haciendo esto, pero no es el aspecto dominante, por decirlo de manera suave. Cultivar buenas relaciones con la empresa privada, por ejemplo, o con los distribuidores de favores presupuestarios y aprobaciones burocráticas del momento, parece mucho más decisivo para el futuro de la universidad que desarrollar el pensamiento crítico de los estudiantes. Sorprendentemente.

Los rectores de universidades de la Iglesia y de universidades privadas no dependen mayormente del presupuesto del gobierno o de las comunidades autónomas. Ello les da un grado de libertad adicional, aunque a su vez deben apoyarse más en el éxito de mercado. La situación para gestores privados y públicos de universidades, sin embargo, es muy parecida desde el punto de vista de la cultura de sus estudiantes y de lo que estos esperan de la universidad.

En ambos casos, la despolitización es una característica si no universal, al menos general. Pocos de los alumnos tienen alguna militancia o incluso simpatía política. Tienden por el contrario a ver la política como un oficio divisivo y sucio, y a sus compañeros que participaban en partidos ya en el Instituto como personas sectarias. El clima general es descrito en el documento como "la desesperanza y la falta de confianza hacia la política que dominan en nuestros días" [3].

Y en cuanto a lo que los estudiantes esperan de la universidad, en realidad no es formación (que incluye sin duda cierta activación política) sino empleabilidad. En el mejor de los casos, la formación es vista como instrumento para la empleabilidad. Tal como se concibe en nuestro medio, la empleabilidad más bien conviene que no incluya la politización. En todo caso, no será de la empresa de 
donde venga el impulso para ella: no la requerirá de los estudiantes. Piénsese en el contraste con las lenguas extranjeras. Muchas universidades han incluido clases e incluso carreras en inglés, y todas han incorporado cursos de idiomas para sus alumnos. Las universidades no estaban preparadas, y la mayor parte de ellas siguen sin estarlo probablemente. Pero la empresa manda. Si ella requiere idiomas para emplear a los graduados de la universidad, la universidad incorporará idiomas a la formación de los estudiantes. Evidentemente, ese requisito no existe con la política.

La politización es entonces algo que la universidad debe poner desde dentro de sí misma, si no contra la empresa y contra sus mismos clientes, los estudiantes, al menos sin contar con mayor ayuda de su parte. Hay un cierto acuerdo entre ellos dos para cotizar en el mercado laboral solo las competencias que hagan al sujeto más maleable, no aquellas que supongan convicciones más firmes.

Esto permite explicar lo que en otro tiempo hubiera sido obvio en el caso del documento de UNIJES sobre la regeneración de la vida democrática en España: que el mismo pronunciamiento exista, ahora requiere ser justificado usando la mitad del documento. En efecto, de los 24 números de la Declaración, 10 se dedican al tema sustancial de hacia qué objetivos reformar la vida pública en España, y el resto a explicar el porqué, el desde dónde, los principios y el compromiso universitario que subyacen a esos 10 puntos. Obviamente esto solo tiene sentido porque la Declaración es un documento inusual. Si fuera habitual que los rectores universitarios hablaran sobre la vida pública, tales cuestiones no requerirían más que un breve recordatorio. Con buena puntería, si los rectores jesuitas deben acusarse de algo en estos temas, es (como muchos otros universitarios) de omisión [2].

Por otra parte, tiene su interés el hecho de que tal omisión termina precisamente con este documento. Sus últimos cuatro puntos enuncian el compromiso de asumir explícitamente la educación cívica y política de todos los alumnos [22], evitando la concentración en los intereses particulares tanto de la Universidad como de los estudiantes (¿de qué sirve un profesional de éxito en una sociedad fracasada?) [23] y abriéndose a actuar desde su identidad propia dentro de un pacto cívico con otros agentes interesados en las reformas que se proponen [24].

\section{LA FILOSOFÍA DE FONDO.}

La Declaración se afinca firmemente sobre la concepción cristiana de la política, que se caracteriza por su continuidad con la ética. Ya decía Aristóteles que quien tiene un proyecto ético para una sociedad debe ser o educador o legislador para ponerlo en marcha (EN, 1179b20ss). Hacerse real en la sociedad y no meramente ser conocido por ella, es la razón de ser de un proyecto moral. 


\section{Raúl GonZÁlez Fabre}

Del educador y del legislador se espera que ejemplifiquen en sí mismos la idea que intentan realizar para todos. ¿Qué valor tiene su propuesta si no muestran con hechos que es ella misma posible, al menos en la escala personal? Tampoco los demás estarían obligados a aceptarla como una alternativa posible por la sola palabra del maestro o del político. Necesitan algunos hechos que hagan creíbles las propuestas porque, como decía el antiguo adagio romano, ad impossibilia nemo tenetur.

La política incluye sin duda las artes de lo colectivo, que constituyen un saber en sí mismo. Pero al mismo tiempo hay una correspondencia entre la calidad ética personal de los políticos, la calidad ética de la política que realizan y la sociedad que resulta de ella. Los viejos políticos tenían muy en cuenta el elemento ejemplificante, que requiere cierta coherencia moral [22]. Los nuevos políticos parecen considerar más los vaivenes de la opinión pública o la conveniencia de cada momento, lo que evidentemente dificulta esa coherencia y finalmente los hace ver como una suerte de invertebrados morales. De ahí una parte de la desconfianza de los jóvenes que el documento detecta "a la vista de las irregularidades y de los escándalos que venimos padeciendo" [3].

La concepción tradicional de la relación entre ética y política constituyó una posesión pacífica de la cultura de Occidente desde los filósofos griegos que respondieron a los sofistas hasta el final de la Edad Media. Maquiavelo vino a romper esa concepción y a inaugurar una época en que el éxito político del gobernante se entiende como independiente de su calidad ética. Una cita del comienzo del capítulo XVIII de El Príncipe puede servir de muestra: "Sin embargo, se ve por experiencia que en nuestros tiempos los príncipes que han hecho grandes cosas son los que han tomado poco en serio la confianza y han aprendido a manipular las mentes humanas con su astucia, para al final vencer a quienes se basaron en la lealtad".

En la versión maquiavélica se encuentra todavía cierta correspondencia entre el bien común y la permanencia del gobernante en el poder. Si el príncipe sigue siéndolo, se evita el mayor de los males de que el Estado debe proteger a la sociedad: la guerra. Se advertirá sin embargo un desplazamiento: en la doctrina precedente, la paz es obra de la justicia (Is 32, 17: "Y el efecto de la justicia será paz; y la labor de la justicia, reposo y seguridad para siempre”). El príncipe que procura la paz ha de gobernar con justicia, y para ello debe ser él mismo justo. ¿Cómo podría realizar la justicia en una sociedad quien fuera personalmente injusto?

Pero en Maquiavelo la paz no es ya obra de la justicia sino, si acaso, de la permanencia en el poder. Esto nos deja en el umbral del siguiente paso, lógicamente obvio: una vez deshechos de la bondad ética como cualidad de la persona, ¿por qué habríamos de conservarla como cualidad de los fines políticos? ¿Qué razón tendría el sujeto dispuesto a lo que fuera por la permanencia en el poder, para querer esa permanencia porque evita la guerra, en vez de por sí misma? Es 
más: ¿qué razón tendría ese sujeto para dejar el poder, incluso si conservarlo requiere la guerra? No es un caso teórico: solo en el último siglo llevamos vistos un número considerables de "líderes" dispuestos a matar (millones, si se tercia) con tal de no irse.

Elevándonos a mayores alturas, el apunte de Maquiavelo permite la aplicación de ideas posteriores como el evolucionismo social. Desde el punto de vista evolucionista la permanencia en el poder es de esos objetivos que se refuerzan a sí mismos: permite emplear el poder para permanecer en el poder. El discurso ético puede tomarse entonces de manera instrumental, esto es, en la medida y de la forma en que ayude a esa permanencia.

La conexión con la ética es obvia en la idea popular de la política. Del político se espera que sea un líder moral que al mismo tiempo muestra a la sociedad lo que ella quiere ser quizás sin saberlo articular bien, y organiza el esfuerzo colectivo para serlo. Ese liderazgo moral, en el sentido común y también en el sentido del común, debe ir unido a un cierto liderazgo ético: si el político niega con sus actos lo que afirma con sus palabras, pierde inevitablemente autoridad moral.

El político maquiavélico lo sabe y sabe que para permanecer en el poder ha de pronunciar el discurso moral del momento y quizás realizar públicamente algunas de las acciones éticas que la gente requiere. Pero, claro, el momento cambia y el político que ha dicho y hecho lo necesario para permanecer en el poder, acaba mostrando con sus contradicciones la debilidad de sus convicciones éticas. El votante termina por descifrarlo: sean cuales sean las finalidades que proclame, su única verdadera finalidad es permanecer en el poder que haya alcanzado. Todas las demás finalidades e ideas que proclama son instrumentales.

El paso del tiempo no resulta entonces neutral, como tendería a serlo si los políticos actuaran por convicción (para estos últimos podría ser incluso positivo, añadiéndoles sabiduría). El político maquiavélico envejece rápidamente conforme sus contradicciones se ponen de manifiesto con el cambio de los tiempos en que cierta palabra y cierta acción resultan convenientes para la permanencia en el poder. Los años lo desprestigian: en vez de añadirle talla moral, muestran a la población cada vez con más claridad que carece de ella.

La población termina pidiendo a gritos políticos jóvenes en quienes todavía se pueda creer. Claro está que se trata de una ilusión: no tienen mucha historia conocida precisamente porque son jóvenes, pero han aprendido el sentido maquiavélico de la política de sus mayores. El paso del tiempo acaba afectando también a la renovación generacional, y pronto el desprestigio es de la actividad entera, no de una cierta generación. A ese punto hemos llegado ya en España, como puede inferirse fácilmente de los primeros números de la Declaración de UNIJES.

Una forma alterna de verlo es desde otra de las ramas con que el maquiavelismo ha adornado la filosofía política moderna: el neoclasicismo. Los agentes son todos maximizadores: de dinero en el sector privado, de poder en el sector público. Ambos objetos de maximización están interrelacionados (y su interrelación es 
obvia en España): con dinero se adquiere incidencia en las decisiones del poder; con poder se adquiere dinero si uno se pone a ello. Ambos sirven para colocar la actividad del otro al servicio de nuestros propósitos, de manera que los dos constituyen importantes ventajas comparativas.

De los políticos profesionales cabe esperar neoclásicamente que intenten maximizar su poder. Por una parte, viven en la competencia por el poder; por otra parte, detentar el poder es lo que les convierte en interlocutores de quienes tienen dinero. Ninguna de las dos cosas es problemática de necesidad. La competencia por el poder siempre es mejor que el monopolio del mismo. Y ser interlocutores de los poderes económicos resulta hasta imprescindible si en esa interlocución el político no va asumir el rol del "consejo de administración de la burguesía para sus asuntos comunes" sino el de promotor del bien común, al menos durante el tiempo en que actúe como político.

Sin embargo, que el problema no sea intrínseco no quiere decir que no pueda existir; no como resultado de la posición en que el servidor público se sitúa sino como mal ejercicio de esa posición. De la relación entre política y economía trataremos en el siguiente epígrafe. De momento, nos ocuparemos de un resultado de las dinámicas competitivas que el documento de UNIJES también considera: la partidización de la vida pública.

En las dinámicas competitivas que nos interesan, se gana adquiriendo poder político en alguno de los diversos ámbitos y por alguno de los diversos mecanismos legitimados por la ley. Como desde el poder se cambian las leyes, eso significa que la tarta para repartirse competitivamente entre los partidos puede extenderse desde el punto de vista lógico, ampliándose primero a toda la vida pública; luego, a toda la vida privada que depende de la contratación con el sector público; y finalmente a toda la vida privada que depende de un permiso del sector público, que en España viene casi a coincidir con toda la vida privada ${ }^{3}$.Cuando se habla de la partidización, se quiere decir eso: los puestos públicos, los contratos públicos para el sector privado, y cada vez más los permisos públicos para parte importante de la actividad privada, dependen de "colaborar" con que los actuales detentadores sigan ganando la competencia por el poder público en cuestión. La política de partido ha engullido ya básicamente al sector público, incluyendo escalones esenciales del poder judicial [12].

Esta es una situación estructuralmente difícil, porque la competencia tiende a violar la dinámica de la virtud. Como decimos, no son en principio contradictorias. Toda competencia, salvo la guerra más salvaje, depende de un acuerdo

\footnotetext{
${ }^{3}$ Es conocido el chiste en que sale Francia pero podría decirse también para España (¿o quizás España debería equipararse a Italia?): Los Estados Unidos se caracterizan por que todo está permitido salvo que esté expresamente prohibido; Francia por que todo está prohibido salvo que esté expresamente permitido; Italia por que todo está permitido, especialmente si está prohibido; Rusia por que todo está prohibido, especialmente si está permitido.
} 
sobre las reglas comunes del juego que es en sí mismo cooperativo, no competitivo. Por ejemplo, en la España actual no se acostumbra matar al adversario político para asegurar el progreso del propio partido: eso se hizo en el pasado reciente (tan reciente como el asesinato de Isaías Carrasco en 2008), pero ya no se hace. Sobre una base de reglas comunes acordadas, se abre el espacio de la competencia. Si las reglas previas garantizan unos mínimos éticos, la competencia abierta por esas reglas respetará esos mínimos a través del respeto a las reglas mismas.

Sin embargo, puede ocurrir que la violación de los contenidos morales de las respectivas reglas sea utilizada como camino para triunfar en la competencia. $\mathrm{O}$ que una vez que ese triunfo ha ocurrido dentro de las reglas, se proceda a cambiar estas para defender mejor el propio predominio. En ambos casos, el resultado es un deterioro ético del sistema de la competencia, cuyas reglas de base bajan un peldaño moral. Dado que los competidores no son mancos, no es que uno baje un peldaño para triunfar, sino que acto seguido todos lo hacen para plantarnos cara en la nueva competencia que nosotros hemos abierto. Por eso, la concepción maquiavélica de la política recomendaría que el primer golpe sea demoledor, si es posible elimine al adversario como tal, porque el segundo golpe probablemente va a ser suyo.

Así pues, mantener la calidad ética de la competencia política es algo que no ocurre espontáneamente: muy a menudo esa calidad no constituye un equilibrio de $\mathrm{Nash}^{4}$ a corto plazo. Hay que hacer un esfuerzo consciente para conservarla y que dé sus frutos como un equilibrio de Nash a largo plazo. El documento de los rectores de UNIJES, sin embargo, se atreve -contracorriente de la cultura política dominante entre los profesionales; de acuerdo con la cultura política de la gente del común- a defender explícitamente la vinculación entre calidad ética y valor moral de una política.

\section{POLÍTICA Y ECONOMÍA.}

Otro elemento que ha contribuido a desprestigiar la actividad política a los ojos de la población es que, cuando la lucha por el poder alcanza su meta, el poder de que se trata es relativamente pequeño en un mundo de fronteras permeables a los flujos generados por el capital. El verdadero poder se encuentra en la economía y todo el desafío político acaba cifrándose en qué hacer para que los capitales vengan en vez de irse, y así produzcan creando empleo en el territorio. Ese es el éxito económico posible del político.

${ }^{4} \mathrm{Nash}$ (2002:59): "An equilibrium point is a n-tuple $\mathrm{S}$ such that each player's mixed strategy maximizes his pay-off if the strategies of the others are held fixed. Thus each player's strategy is optimal against those of the others". 


\section{Raúl González Fabre}

El capital genera flujos transnacionales varios cuyo objeto es siempre incrementar las ganancias y reinvertirlas, acumulándose para reproducirse a sí mismo, que diría Marx (1978:cap. 21). Junto con el flujo del capital mismo, está el de las mercancías que produce, el de las imágenes con que promociona esas mercancías, el de los turistas a los que vende servicios, el de los trabajadores cualificados que necesita para tareas directivas e incluso el de los trabajadores no mayormente cualificados que precisa para contener el precio del trabajo en niveles competitivos (ver Servicio de Estudios La Caixa (2006:51)).

La permeabilidad de las fronteras al capital y a otros varios flujos generados por él desdibuja así el poder sobre el territorio: de gobernar esos flujos, el poder pasa a navegarlos. Quien, de entre los votantes, espere que el gobierno gobierne puede prepararse para una decepción. De ahí que el Documento que comentamos sitúe entre las causas de la pérdida de confianza "la crisis actual y (...) las situaciones de penuria que tantas personas y familias sufren, en un escenario que parece desbordar la capacidad de nuestros gobernantes y de la clase política en general.” [3]

No es en realidad una impotencia coyuntural nacida del hecho de tener malos políticos; es una impotencia estructural derivada de tener mercados globales con estados nacionales. Por eso, las únicas respuestas posibles son la llamada del Santo Padre a la constitución de una Autoridad Política Mundial con poder para hacer valer sus decisiones $(\mathrm{CV}, 67)$, que supone seguir adelante con la globalización haciéndola política además de económica; o bien volver al nacionalismo económico, como proponen en Europa toda una serie de partidos neopopulistas, filofascistas, comunistas, etc.; nacionalismo económico sobre el cual, y solo sobre el cual, puede fundarse el nacionalismo político.

Por supuesto, en esta última opción se gana en gobernabilidad nacional pero se pierde en eficiencia económica, de manera que, aparte del temor que pueda dar ser gobernados por sus propugnadores, está el miedo de qué pasará con esos países cuando la tortilla se dé la vuelta y la globalización retorne. Las fábricas abandonadas en la Europa del Este nos ofrecen una pista de por qué la alternativa católica es más interesante que la neopopulista aunque se trate de un tiro más largo.

Sosteniendo la subordinación de la economía a la política [9], el documento de los rectores de UNIJES navega también contracorriente. Lo hace al proponer que el bien individual, tal como cada uno lo persiga en el mercado, ha de estar ordenado al bien común a través de poderes públicos que eviten o corrijan los abusos de poderes privados. La experiencia contemporánea ${ }^{5}$ es quizás más radical que la expresión que encontramos aquí. La crisis ha devuelto a muchas personas la impresión de que el lugar posible de la libertad, donde cabe decidir un proyecto

\footnotetext{
${ }^{5}$ Es ilustrativa a este respecto una secuencia de la película Margin Call (2011). Hacia el minuto 85, un diálogo respecto a los riesgos, transcurre:

- En ese momento no parecía que hubiera mucha elección.

- Nunca la hay.
} 
y llevarlo adelante, es la política, mientras que la economía es un lugar de necesidad respecto al que tenemos poca elección.

En ese contexto, afirmar la prioridad de lo político sobre lo económico significa, también, recuperar la primacía de la libertad sobre la necesidad, del proyecto colectivo libremente asumido sobre la mera gerencia del estado de cosas dado por dinámicas económicas globales. Ello permite comprender mejor por qué el documento propone reformar el Estado nacional: no es solo que un Estado mejor organizado será más eficiente en la competencia de los mercados globalizados; se trata también de que lo necesitamos como instrumento de un proyecto común capaz de poner esos mercados al servicio de la persona.

\section{PATRIMONIALISMO.}

El último punto que mencionaremos aquí se refiere a lo que Francis Fukuyama (2011) llama "patrimonialismo", que viene a consistir en que los mecanismos abstractos de gobierno de países, organizaciones, etc., ceden ante las relaciones personales concretas, de manera que son respetados o violados según hacerlo convenga a la relación personal del caso. La ley, la norma, la estrategia, la política... todo ello se dobla si es preciso tan pronto como aparece en escena una relación personal pidiendo ser reforzada mediante el uso de lo público, no digamos si se trata de una relación familiar o de amistad.

Esto constituye el exacto opuesto de la modernidad vigente en materia de orden social. Esa modernidad, nacida de la Revolución Francesa, consiste en reglas iguales para todos formuladas de acuerdo no a una voluntad arbitraria sino a una racionalidad universalista. Típicamente, la racionalidad de que se trata está contenida en la primera formulación del imperativo categórico kantiano (1785 [1993]: 30): la máxima de la acción, si se sigue por todos, ha de conducir a un estado de cosas deseable para cualquier mente racional.

La idea del patrimonialismo, a veces llamado también familismo ${ }^{6}$, consiste en que las reglas son distintas para los pertenecientes a mi familia y para los demás. Suele ser juzgado como "corrupción" del esquema moderno o como la base para ella, pero en realidad el familismo precede a la modernidad. Proviene de los tiempos en que la Humanidad funcionaba en tribus de cazadores-recolectores de muy pocos cientos de personas estrechamente emparentadas entre sí. En esas circunstancias, las fronteras del "nosotros" y el "ellos" quedaban bien delimitadas por contornos familiares. Esto es así hasta el punto de que en muchas lenguas tribales el nombre de la tribu es la misma palabra que significa "gente", lo cual indica en qué aprecio se tiene a los de fuera.

\footnotetext{
${ }^{6}$ Por ejemplo, por Edward C. Banfield (1958).
} 


\section{Raúl GonZÁlez Fabre}

La especie Homo sapiens sapiens puede contar unos 200 mil años de antigüedad (pero es a su vez la sucesora de especies anteriores del mismo género que tenían un modo de vida semejante; Pinker(2011)). Las ciudades, donde aparecieron por primera vez poblaciones más numerosas gobernadas por estructuras sociales abstractas, son de hace unos 15 mil años a lo más. Se notará entonces que nuestro cerebro evolucionó para tener éxito en contextos tribales poco numerosos, donde todos eran más o menos familia. El éxito que hayamos podido alcanzar gestionando estructuras abstractas es resultado de la evolución cultural, no de la evolución biológica.

No es solo que el patrimonialismo está inscrito en la constitución de nuestro cerebro, sino que es el portador de una moralidad, no de la corrupción de una moralidad. No consiste solo en acumular un "patrimonio" de favores hechos y dineros dispensados, con el fin de que haya muchos debiéndome algo. La moral propia del patrimonialismo es la de una comunidad: a cada cual según su necesidad, de cada cual según su capacidad.

Notamos su influencia cuando, estando en un puesto donde debemos aplicar ciertas reglas abstractas, se nos acerca alguien que es "familia" nuestra (miembro efectivamente de la familia, amigo, recomendado de un amigo, etc.). Si lo que nos pide requiere torcer en alguna manera las reglas, los procedimientos para aplicarlas, o ambos, puede que cedamos a ello o no, pero ciertamente si no lo hacemos con alguien cercano es posible que aparezca cierto malestar moral. Es posible también que la otra persona no comprenda que pudiendo nosotros y necesitando ella, no lo hayamos hecho. Cabe que después del suceso, la relación ya no sea la misma porque nos hemos mostrado como un socio poco confiable en la comunidad a la que ambos pertenecíamos.

Otra manera de decir lo mismo, invirtiendo los roles, ocurre cuando entramos en algún conflicto que requiere la intervención de un organismo, público o privado, que se supone regido por normas abstractas. En ese caso, lo primero que nos viene a la cabeza es "¿qué norma me ampara?", o bien "¿a quién conozco yo allí?" Si por defecto nos viene a la mente la segunda pregunta, y solo en caso de que no podamos entablar un vínculo personal con alguien nos planteamos la primera, en realidad somos de moralidad familista.

Anterior en el tiempo a la modernidad que habitamos (la cual en su actual forma igualitaria nació a finales del s. XVIII), el patrimonialismo o familismo resulta sin embargo extremadamente disolvente de las instituciones modernas. No se trata de que les roba el terreno del discurso, afirmándose como una moralidad superior, por encima de la moralidad moderna de reglas abstractas a las que todos obedecemos por igual. No; para encontrar desafíos de ese tipo hay que ir a la saga de El Padrino, esto es, al espacio clandestino de la ilegalidad que se afirma a sí misma.

Más frecuente es que el patrimonialismo ceda el espacio del discurso público a alguna forma de modernidad (la más particularista de las socialmente aceptables 
es quizás el nacionalismo que hemos mencionado: "La France aux Français"), pero se apropie del mismo espacio público con sus prácticas. Se dice una cosa, se hace otra. El resultado es que el orden moderno viene a constituir un ideal deseable (porque su eficiencia se reconoce en el discurso, el cual domina) pero inverosímil (porque en la realidad las prácticas patrimonialistas constantemente tuercen las reglas modernas a favor de los mejor conectados).

Esta dicotomía es evolucionariamente estable. Si uno se empeña en actuar como un sujeto plenamente moderno en un entorno donde la dicotomía predomina, pronto se encontrará sin el apoyo familiar y de los amigos tan importante para el éxito social en ese contexto. Pero si uno se empeña en hablar como un sujeto plenamente patrimonialista, y ser coherente por el otro lado, pasará por un atorrante a quien no se le puede dar un micrófono porque defiende lo contrario de lo que todo el mundo dice (aunque la mayoría lo haga, tan pronto como la oportunidad aparece).

Que la sociedad española funciona así (como todas las del sur de Europa, por otra parte), es algo de lo que ya no cabe duda. Si alguna vez conseguimos disimularlo para consumo de la Europa del Norte, ese tiempo ya pasó. Las altas instancias del Estado con su manejo de los casos judiciales que las afectan, el gobierno con sus luchas internas y sus indultos, la patronal, los sindicatos, los partidos, las empresas oligopolísticas... y seguramente también una infinidad de otras organizaciones privadas de matriz nacional y de personas "con buenos contactos", han demostrado funcionar por relaciones privadas antes que por las normas comunes y públicas, que sin embargo existen y a las que todos prestamos pleitesía verbal.

Como decimos, esa primera base de desarticulación de las instituciones modernas constituye de hecho una moral familista con su concepto de lo bueno. Es un concepto de lo bueno más perceptible, más real para el sujeto, que el concepto contenido en las relaciones públicas abstractas mandadas por la institucionalidad. Por lo que dijimos de sus raíces físicas evolutivas, no es raro que tal concepto consistente en hacer "lo bueno para los míos", esté muy cerca de nuestras intuiciones morales primeras. Si además la idea de hacer "lo correcto según reglas abstractas" está tocada por una inverosimilitud social modelada por todo tipo de magistraturas, también se entiende que la principal defensa que le quedaba a la moral necesaria para que funcionen las instituciones -su capacidad para el éxito en la evolución cultural- puede ser derrotada en el terreno cultural de las prácticas precisamente.

Si nos hallamos ante una moralidad, no ante la corrupción de una moralidad, ¿qué está entonces mal con ella? Lo que Michael Walzer (1983) señalaba atinadamente: que viola la separación entre las esferas de validez de los respectivos conceptos de justicia. Si hemos acordado (el discurso es importante) que el ámbito público se regirá por una ley igual para todos y en el ámbito privado cada cual podrá desarrollar hasta donde quiera una ética comunitaria, hay un mal moral 
en aplicar los criterios de esa ética comunitaria a las decisiones en lo público, aunque los valores éticos de lo comunitario sean en sí mismos genuinos (dentro de su esfera acordada).

Sobre ese primer mal moral se asientan formas diversas de corrupción que ocurren incluso cuando la relación personal está ausente. Una vez que el sistema institucional se ha hecho saltar usando una moralidad comunitaria auténticamente reconocible como moral, entonces puede ser parasitado por otras motivaciones que nadie defendería como moralmente válidas. Por ejemplo, puede ser parasitado por el afán de lucro o, todavía más frecuentemente entre nosotros, por el afán de poder.

Casi cada vez que en el documento de UNIJES se detecta una diferencia entre lo que un agente en la vida pública dice y lo que hace, ese segundo paso en la corrupción está presente. Pero él no constituye una anomalía inmediatamente detectada y expulsada del sistema porque constituye el segundo, no el primer paso de separación de la moralidad requerida para que funcionen las instituciones. El primer paso es mucho más general en la población, éticamente mucho más fácil de aprobar por ella, y sin duda, allí ocurre el grueso de la disolución de la institucionalidad moderna. Por así decirlo, el segundo paso puede prosperar porque ataca las ruinas, en pie pero ruinas, que dejó el primero.

Evidentemente, el resultado de este proceso es una calidad de las instituciones todavía peor de lo que sería de temer por el dominio de la economía sobre la política de que hablamos arriba. Esto último ya establece una impotencia importante para quienes gobiernan la polis. Pero la impotencia se multiplica si se le unen todos los "intereses creados" que deben respetarse, de personas y grupos patrimonialistas que no funcionan según una ley universal pensada para el bien común sino según su capacidad de torcer a su favor la formulación o la aplicación de la ley.

En términos económicos, el resultado es la abundancia en España de lo que Adam Smith (1776 [2000]:203ss) llamaría rentistas, que no obtienen su riqueza ni de la remuneración real de su trabajo ni de los beneficios de sus empresas en mercados competitivos. La obtienen de su capacidad para usar dinero, posición social, poder electoral, contactos políticos y semejantes, para asegurar que el patrimonio siga afluyendo hacia ellos aunque no se derive ningún bien social. La forma en que el patrimonio afluye puede ser muy variada: sueldos o pensiones por falsos trabajos, oligopolios que permiten inflar las utilidades a costa de la sociedad, sobres que circulan de mano a mano, subsidios públicos atribuidos por cercanías personales o políticas, cargos que se reparten entre los amigos, impuestos debidos que no se inspeccionan, formas diversas de do ut des, etc.

El otro resultado obvio es una economía ineficiente comparada con sus competidores, que aflora en una tasa de desempleo formidable. El trabajo y el capital de cualquier verdadero negocio productivo en España deben financiar las rentas que la ley establece más las muchas rentas ilegales pero bien apoyadas. Evidente- 
mente ello hace menos competitivo al negocio español frente a sus posibles adversarios extranjeros, porque el burro solo aguanta un cierto número de albardas; de ahí en adelante, es aplastado por el peso de la carga.

Curiosamente, la respuesta para aumentar la competitividad parece dirigirse a recortar las rentas recibidas por mecanismos legítimos que el Estado ha establecido para que la redistribución ocurra. Los mecanismos también legales pero menos legítimos (porque no son el resultado de una búsqueda del interés general sino de la fuerza rentista de un grupo de presión) y los mecanismos abiertamente ilegales, han quedado para después. De hecho, parece que la mayor parte de ellos hubieran quedado para nunca porque precisamente el respaldo de un grupo concentrado de interés anuncia mayor conflicto político que si se tocan intereses más generales, por tanto más difíciles de organizar (cfr. Olson(1971)).

Como remedio fundamental a las muy diversas variantes de este patrimonialismo, el documento propone la transparencia ([13] referida al conjunto de los actores; [14] respecto a la financiación de los partidos; [16] para la administración pública; [17] en particular para la contratación pública y para la inspección sobre esos contratos; [18] respecto a la economía sumergida; [19] respecto a la fiscalidad; [20] para los medios de comunicación social y su financiamiento). Tanto insistir en la transparencia y en sinónimos de uso como sacar a la luz o la no opacidad, se debe a nuestro entender a que lo adecuado, lo acordado acerca de cómo deben funcionar las cosas, domina el discurso público de manera que la conducta patrimonialista (represente ella una moralidad compartida o, construida sobre ella, consista en la mera negación de cualquier moralidad) debe permanecer clandestina. Dicho con palabras de Kant (1795 [1993]:185):

Hay algo incorrecto en una máxima de conducta que no puedo divulgar sin derrotar su propósito, una máxima que debe por tanto mantenerse secreta para tener éxito, y que no puedo reconocer en público sin levantar infaliblemente la oposición de todos. Esta resistencia necesaria y universal con que todo el mundo se me opondría, una resistencia evidente por tanto a priori, no puede deberse a otra causa que la injusticia con que tal máxima amenaza a todo el mundo.

Tiene pues sentido ético obligar legalmente a la transparencia. En la medida de esa obligación legal, la transparencia puede resultar en un cambio de comportamientos que haga a su vez moralmente verosímil la Modernidad para las generaciones venideras.

\section{PROPUESTAS ESTRUCTURALES.}

La Declaración plantea además una serie de cambios estructurales en la vida política española, que no solo atienden a superar las limitaciones nacidas de los tres puntos anteriores (y en ese sentido a recuperar el espíritu de la Constitución 


\section{Raúl González Fabre}

de 1978) sino también a ir más allá en el desarrollo modernizador del país. No entraremos en su detalle, entre otras cosas porque será más rápido para el lector verlos directamente en los números [12] al [20] de la Declaración. Por ejemplo en ese capítulo entra la propuesta de diálogo sobre la ordenación del territorio. [15]

Aunque no entremos en el detalle, queremos no obstante comentar algo sobre los sujetos y los medios que afecta a todas las propuestas de la Declaración, las que miran a sanearnos a partir de lo que nos propusimos ser colectivamente en el pasado y las que miran a proseguir en salud pactando nuevas estructuras de convivencia más eficaces para participar en la globalización con nuestro Estado nacional.

Quizás el punto de partida sea notar que en el mismo título de la Declaración se utiliza la palabra "regeneración". Esa es una palabra difícil en nuestro vocabulario político: los términos inevitablemente llevan consigo, aunque no se pretenda, una historia. Incluso si prescindimos de la burla a la palabra que fue nuestro último "regeneracionismo" conocido (el que dejó el poder judicial a los partidos, contra el espíritu de la Constitución), y nos quedamos con el regeneracionismo menos engañoso de hace un siglo largo, el de Joaquín Costa, notamos que el principal de sus problemas consiste en que no consiguió la regeneración que anhelaba.

Sus ideas hicieron mucho camino, pero principalmente encarnadas en las víctimas del sistema, no primero en quienes se beneficiaban de él. Con otras palabras, las ideas de la regeneración alentaron la revolución, porque la revolución tenía más sujeto real que la regeneración. Cuando por fin las élites hicieron la modernización de España, después de décadas de resistencia en minoría hasta llegar a la guerra civil, lo hicieron sin duda bajo la convicción de las ideas regeneracionistas y otras semejantes (principalmente del campo católico) pero también, y quizás más, bajo la presión de una población cuyo "gen" revolucionario debían desactivar para sobrevivir como élites.

Con esta visión del pasado simplificada a un par de párrafos podrá estarse sustancialmente de acuerdo o no, pero me parece más difícil contradecir los enunciados teóricos que la subyacen:

- La transformación social intencional es producto combinado de la convicción, del interés y del miedo. Quienes están en posiciones de poder político o económico para cambiar las cosas, funcionan por una o varias de esas motivaciones.

- Quienes tienen mejores motivos para crear la presión que inspira miedo son las víctimas del sistema. También los competidores externos al sistema pueden producir un efecto parecido. En todo caso, ambos pueden amenazar a las élites con dejar de serlo.

La Declaración de UNIJES propone el diálogo entre los diversos agentes preocupados por la modernización del país y los agentes que detentan distintos po- 
deres, con el fin de realizar las reformas necesarias. El documento habla mucho en términos de convicción, bastante menos en términos de interés, y casi nada en términos de presión desde las víctimas o desde los competidores exteriores. En ese sentido, UNIJES se ofrece para un diálogo cuyo sentido último quizás sea evitar los grandes conflictos sociales y económicos que se ven formarse amenazadoramente en el horizonte. Implícita en la Declaración se encuentra la idea de que aún estamos a tiempo.

La experiencia positiva de referencia probablemente sea la Transición de 1978; las experiencias negativas, el siglo anterior de fracasos en producir la modernización por el diálogo. El problema motivacional consiste en si los beneficiarios públicos y privados del actual estado de cosas perciben la amenaza suficientemente como para participar en el diálogo propuesto. Salvo los pocos agentes que actúen por convicción (siempre los ha habido; también hace un siglo), el resto reaccionará más por miedo que por otra cosa. Y en ese capítulo la Declaración de UNIJES no tiene mucho que decir, excepto la muy preocupante constatación de que la población en general, y los jóvenes en particular, desconfían de la política y la desprecian. Debería ser suficiente para asustar a cualquiera, pero no sabemos si será así, o si esperaremos en el futuro documentos de UNIJES más explícitos sobre el rol de las víctimas.

\section{BIBLIOGRAFÍA.}

ARISTOTLE, W. D. ROSS, ET AL. (2009), The Nicomachean ethics, Oxford University Press, Oxford, New York.

BANFIELD, E. C. (1958), The moral basis of a backward society. Glencoe, Ill., Free Press.

BENEDICTO XVI (2009), Carta encíclica Caritas in Veritate en: http://www. vatican.va/holy_father/benedict_xvi/encyclicals/documents/hf_ben-xvi_ enc_20090629_caritas-in-veritate_sp.html.

FUKUYAMA, F. (2011), The origins of political order: from prehuman times to the French Revolution, Farrar, Straus and Giroux, New York,

GONZÁLEZ FABRE, R. (1996), "Las estructuras culturales de la corrupción en Venezuela”, en ZAÑARTU, M. (1996), Eficiencia, corrupción y crecimiento con equidad, Universidad de Deusto, Bilbao, pp. 49-58.

KAHNEMAN, D. (2011), Thinking, fast and slow, Farrar, Straus and Giroux, New York.

KANT, I. and J. W. ELLINGTON (1785 [1993]), Grounding for the metaphysics of morals; with, On a supposed right to lie because of philanthropic concerns, Hackett Pub. Co., Indianapolis

KANT, I. (1795 [1903]), Perpetual peace; a philosophical essay, S. Sonnenschein, London. 
MACHIAVELLI, N. (1998 [1532]), The prince, University of Chicago Press, Chicago, Ill.,

MARX, K., B. FOWKES, ET AL. (1978 [1885]), Capital: a critique of political economy. vol 2, Penguin Books in association with New Left Review, London; New York, N.Y.,

NASH, J. F., H. W. KUHN, ET AL. (2002), The essential John Nash, Princeton University, Press.Princeton, N.J.

OLSON, M. (1971), The logic of collective action; public goods and the theory of groups, Harvard University Press, Cambridge, Mass.,

PINKER, S. (2011), The better angels of our nature: why violence has declined, Viking, New York.

SERVICIO DE ESTUDIOS DE LA CAIXA (2006), "Los efectos de la inmigración sobre el empleo y los salarios" en Informe mensual octubre 2006. Barcelona.

SMITH, A. and E.CANNAN (1776 [2000]), The wealth of nations, Modern Library, New York.

WALZER, M.(1983), Spheres of justice: a defense of pluralism and equality, Basic Books, New York. 


\section{ANEXO: DECLARACIÓN DE UNIJES "POR LA REGENERACIÓN DE LA VIDA DEMOCRÁTICA EN ESPAÑA”. JULIO 2013.}

\section{A. POR QUÉ ESTA DECLARACIÓN CONJUNTA.}

1. UNIJES, que agrupa todos los centros universitarios de la Compañía de Jesús en España, quiere ofrecer una reflexión y expresar unas palabras sobre la necesaria y urgente regeneración de nuestra vida política. Nos han movido a ello dos razones: la situación de crisis económica y de deterioro político por la que atraviesa nuestro país, y nuestra propia responsabilidad como centros universitarios (cuya misión incluye la formación de una parte de la ciudadanía, las tareas de investigación que crean conocimiento, y la proyección y divulgación de este a través del diálogo social).

Por ello, ante una situación social y política que preocupa profundamente a una parte importante de la ciudadanía, en un momento que requiere de la política actitudes honestas, actuaciones decididas y compromisos duraderos, queremos contribuir al diálogo común desde nuestra aportación específica.

2. Como centros vinculados a la Compañía de Jesús e inspirados en un humanismo cristiano pero abierto a otras sensibilidades distintas a la nuestra, queremos comenzar reconociendo que no siempre hemos estado a la altura de las circunstancias, aunque solo fuese por omisión o por descuido, lo cual nos exige una revisión autocrítica compartida con todo el sector universitario. Nuestra intención ahora no es repetir las grandes declaraciones de la Iglesia o de la Compañía de Jesús, sino algo más concreto: reaccionar ante la situación delicada por la que atravesamos en nuestro país y expresar públicamente nuestra palabra y nuestro compromiso, conscientes de que la sociedad espera y exige de nosotros una voz crítica y razonable, al servicio de la política digna y del bien común.

\section{B. DESDE DÓNDE NOS PRONUNCIAMOS.}

3. Nuestro punto de partida es la desesperanza y la falta de confianza hacia la política que dominan en nuestros días. Este sentimiento se agrava por la crisis actual y por las situaciones de penuria que tantas personas y familias sufren, en un escenario que parece desbordar la capacidad de nuestros gobernantes y de la clase política en general. Y se agrava aún más, a la vista de las irregularidades y de los escándalos que venimos padeciendo.

4. Existe una nueva y persistente demanda social que recorre nuestro país, así como otras sociedades europeas. Junto a la desazón y a la desconfianza, se mani- 
fiestan nuevas iniciativas y anhelos de participación política de muchos grupos y personas. En el fondo de todo ello, late una conciencia ética que responde a valores arraigados en nuestra sociedad, tan necesarios para la regeneración de la política y de la vida pública. Pero tampoco debemos olvidar, por contraste, que durante estos últimos años hemos visto cómo se "corrompían" ciertas bases sociales y culturales de nuestra vida común.

5. Partimos también de nuestra condición de universitarios, conscientes de que de la universidad se espera que favorezca la búsqueda de propuestas de solución ante los retos de una sociedad cambiante y en crisis. En estos tiempos difíciles, en que no abundan los análisis certeros ni las ideas creativas, nos resistimos a aceptar como algo inevitable que no existan valores y criterios éticos, o a resignarnos y desinteresarnos por la vida común.

6. Por último, como centros vinculados a la Compañía de Jesús e inspirados en un humanismo cristiano y abierto, deseamos contribuir al diálogo común desde nuestra aportación específica, desde nuestra vocación de servicio a la fe y a la promoción de la justicia, y de presencia en terrenos de frontera (Compañía de Jesús, Congregación General XXXV, 2008)

\section{QUÉ PRINCIPIOS INSPIRAN NUESTRA REFLEXIÓN.}

7. Vivir juntos como sociedad que comparte espacios, tradiciones e intercambios exige que rehabilitemos la política y su dignidad: eso es, la política como servicio a la vida común, a la vida de todos, y no como mera lucha por el poder, por conquistarlo y ejercerlo.

La política debe orientarse a promover la justicia en la sociedad, en una sociedad que siempre es plural y donde abundan las desigualdades. Por eso, la política ha de prestar especial atención a las personas afectadas por la injusticia.

8. La política, el arte de vivir juntos y de pensar juntos la vida común, debe hacernos más humanos. Su centro ha de ser la persona humana; su fin, el desarrollo integral de todos. Para fundamentar este desarrollo, hemos de partir de una auténtica visión de lo humano, de un humanismo nuevo. Ahora bien, en una sociedad plural formada por personas libres, la política no ha de pretender organizar la vida de todos, sino crear las condiciones para que cada uno pueda, en libertad, hacer realidad sus aspiraciones legítimas.

Este conjunto de condiciones para una convivencia de todos en libertad es lo que constituye el bien común, que es responsabilidad de todos, pero de manera 
más directa de quienes ejercen legítimamente el poder político. Así lo reconoce la tradición de la Iglesia, de forma expresa en el Concilio Vaticano II (Gaudium et Spes n. 74):

"Los hombres, la familia y los distintos grupos que constituyen la comunidad civil tienen conciencia de su propia insuficiencia para realizar una vida plenamente humana y se dan cuenta de la necesidad de una comunidad más amplia, en la que todos conjuguen día tras día sus propias fuerzas para realizar cada vez mejor el bien común.”

9. Diversos actores mundiales, entre ellos la Iglesia católica, manifiestan la necesidad de que la política, tal como se define aquí, recupere su espacio ante la economía. Esta afirmación resulta más urgente en el contexto de una crisis en que los mercados parecen imponer su lógica sobre los gobiernos y sobre los pueblos. Por contra, esto no puede implicar el rechazo de la economía ni de sus actores. La actividad económica -con empresas, empresarios y emprendedores como activo social clave- es la fuente de creación de riqueza y de puestos de trabajo, y el cauce para la producción de bienes y servicios para todos; en ella, cada cual se orienta según sus legítimas aspiraciones. Si la política ha de recuperar espacio a la economía es para enmarcar estas actividades particulares dentro del bien común, de los intereses generales de la sociedad: y lo hace encauzando la actividad económica de muchos, corrigiendo las disfunciones y el abuso de posiciones de poder que el juego de la libertad de muchos inevitablemente genera, atendiendo especialmente a los más vulnerables.

10. Esta importancia de la política conlleva la responsabilidad de todo ciudadano hacia el bien común de la sociedad actual y de las futuras generaciones, aunque no sienta una vocación concreta a la actividad política. Si los miembros de una sociedad solo se consideran sujetos particulares, si se desentienden de los intereses generales e incluso ven en lo público un obstáculo que hay que procurar sortear, difícilmente se podrá hablar de ciudadanía y se producirá una ruptura inevitable entre la sociedad y el Estado.

\section{ALGUNAS PROPUESTAS Y LÍNEAS DE TRABAJO PARA UNA AUTÉNTICA REGENERACIÓN DE LA VIDA POLÍTICA.}

11. Los principios políticos y sociales que acabamos de presentar pueden parecer demasiado utópicos. Nosotros creemos que este es el horizonte de una auténtica política. Es cierto que la política que vemos a nuestro alrededor está lejos de este horizonte. De ahí nuestra preocupación. Por ello, queremos enumerar algunas tareas que ayudarían a hacerlo más cercano y más real en la vida política de nuestras 
sociedades. No pretendemos ofrecer un programa exhaustivo, sino solo proponer algunas tareas que nos parecen urgentes y prioritarias para devolver la dignidad a la política y para recuperar esta confianza que tanto echamos de menos.

12. Urge una separación de los poderes públicos más efectiva y real. La independencia del poder judicial es un asunto de la mayor importancia, por lo que se debe evitar la politización partidista o corporativa de los órganos de gobierno de la judicatura, renunciar al sistema de cuotas, establecer procedimientos que garanticen la profesionalidad y la pluralidad, y dotar el estamento judicial de los recursos necesarios y de los propios sistemas de accountability.

13. El compromiso para una mayor transparencia de todos los actores es fundamental para la regeneración de la vida pública. Si las instituciones, los partidos políticos y todos los poderes públicos se someten a una regulación clara y exigente de la transparencia, con buenas prácticas de control y rendición pública de cuentas y evaluación, toda la sociedad habrá ganado en un área especialmente sensible para la regeneración democrática. De este modo, se avanzará significativamente en la vivencia de unos valores sociales compartidos.

14. Los partidos políticos -expresión constitucionalizada de nuestro pluralismo político, pero tan solo un medio al servicio de ese pluralismo- son actores esenciales de la vida política y han hecho posible gran parte del desarrollo social y político que hoy disfrutamos.

Es necesario que actúen no subordinando el bien común a los intereses de partido. También es urgente que imperen los criterios de claridad y transparencia en la forma y en el control de su financiación. El excesivo peso de la partitocracia debe ser reequilibrado; a ello ayudaría una reforma electoral que reforzara la participación ciudadana, redujera el poder de los aparatos de los partidos y confiriera mayor protagonismo a la vida parlamentaria.

15. Para unos y para otros, la ordenación territorial del Estado es fuente de decepción continua y de tensión. Desde la afirmación serena, pero consistente, de una realidad plural de España y de una Constitución abierta a las reformas necesarias, hemos de recuperar los consensos prácticos -también el consenso constitucional- que hagan viable un sistema que, sin llegar a ser perfecto, obtenga un mayor grado de aceptación que el actual y que garantice los grados deseables de cohesión y de solidaridad. Para ello, si queremos ser una sociedad democráticamente avanzada y respetuosa de los derechos humanos de todos, el diálogo es necesario y ha de ser responsablemente promovido y cuidado por todos los actores sociales y políticos. 
16. Los países se vertebran con una administración pública de calidad y transparente. La regeneración de la vida pública no será posible sin el fortalecimiento y la profesionalización de la administración. Hay que garantizar la aplicación de los principios constitucionales de mérito y capacidad en la gestión del empleo público, así como la evaluación del trabajo, la integridad de los comportamientos, la justa retribución y el refuerzo de la consideración social de los servidores públicos. La condición de servidor público requiere ser especialmente exigentes en el control y en la eventual sanción de los comportamientos injustos y éticamente reprobables. Todas estas medidas deberían armonizarse con una reforma de las administraciones públicas orientada a ganar eficacia y eficiencia en el quehacer público.

17. En la normativa reguladora de la contratación del sector público, son imprescindibles la estabilidad y la transparencia. Cuando se producen supuestos de corrupción relacionados con la contratación pública, estos no son principalmente el resultado de una regulación deficiente de la misma, sino de debilidades en su aplicación.

La objetividad y la transparencia solo pueden garantizarse con una adecuada función inspectora e interventora a cargo de poderes públicos independientes.

18. Por sus repetidas y evidentes conexiones con gran parte de los escándalos de corrupción política, la llamada "economía sumergida" debe salir a la luz, aunque la problemática sea más amplia. Esta es una condición necesaria y urgente para prevenir y combatir efectivamente la corrupción, y para promover la justicia fiscal y la financiación equitativa de las cargas públicas.

19. Debe reformarse el sistema fiscal para que esté efectivamente al servicio de todos, con equidad en el reparto de las cargas mediante una progresividad adecuada, y evitando las posibilidades o los incentivos a la evasión, a la opacidad o al descontrol. El fraude fiscal no solo daña la vida común, sino que además incentiva la corrupción política. La existencia de paraísos fiscales, sin intercambio automático de información, resulta inadmisible. Todo ello ayudaría a encarar también la financiación irregular de los partidos políticos. Necesitamos un mayor consenso cívico para combatir el fraude y para fomentar los valores del comportamiento cívico y de la solidaridad.

20. La libertad de expresión y la libertad de información han de ejercerse responsablemente. Los propios medios han de impulsar un sistema de autocontrol que responda a buenas prácticas aceptadas y a comités de ética informativa, encargados de proteger y vigilar tanto la libertad de expresión como la veracidad de las informaciones y la debida utilización de las mismas, y que evite su uso oportunista o par- 


\section{Raúl GonZÁlez Fabre}

tidista, como sucede tantas veces hoy en día. Los medios de comunicación públicos y privados son instrumentos clave para la democracia y para la tutela del valor de la auténtica política, y han de recuperar de manera nítida su función de servicio social. Es deseable, además, una transparencia en su gestión, financiación y control.

\section{E. NUESTRO COMPROMISO UNIVERSITARIO.}

21. Nuestro compromiso radica en que todos los miembros de nuestras comunidades académicas - estudiantes, profesorado, personal de administración y servicios-, además de ser competentes y buenos profesionales, sean también ciudadanos conscientes y comprometidos en la construcción de una sociedad más libre, más democrática, más próspera, más solidaria y fundamentalmente más justa. Esta es nuestra responsabilidad y, por ello, queremos que nuestras energías e iniciativas contribuyan más decididamente a inspirar y a promover la regeneración de nuestra vida pública, en especial de la acción política y del compromiso ciudadano.

22. Un aspecto fundamental de nuestra misión universitaria ha de ser, por consiguiente, la educación cívica y política de los estudiantes, para que puedan cumplir su misión en la vida social y para que, si optan por ejercer la actividad política, se preparen adecuadamente para este servicio público, subordinando para ello otros intereses, incluidas las expectativas de ganar más. Este criterio moderador debería regir para todos, aunque sea especialmente relevante para quienes dedican su vida al servicio público, cuya ejemplaridad es muy necesaria.

23. Las universidades hemos de recordar y reforzar que nuestra misión es universal, y que las visiones y los intereses localistas, o la búsqueda de un éxito medido por criterios solo competitivos, no forman parte de nuestra razón de ser. Las actitudes y las conductas orientadas únicamente a alcanzar cotas de poder, lucro o prestigio resultan incompatibles con nuestra misión.

24. Todas las universidades, y particularmente las nuestras, han de apostar por abrir horizontes, como dice el P. Adolfo Nicolás, superior general de la Compañía de Jesús, "desde la actitud humilde del que pretende con honradez que el saber se convierta en un sólido instrumento de servicio". Las universidades jesuitas podemos y debemos contribuir -a través de la docencia, la investigación y la proyección social- al desarrollo de una formación humanista amplia y abierta, a la difusión de una verdad crítica, al diálogo social y a la promoción de la justicia. Si, como presumimos, muchos otros actores sociales están en sintonía con esta declaración, cabe impulsar un gran pacto cívico que nos reanime y nos vincule a todos en un proyecto de alcance para mejorar nuestra vida política y nuestra convivencia. 